\title{
POTASSIUM PERMANGANATE AS OXIDANT IN THE COD TEST FOR SALINE WATER SAMPLES
}

\author{
Chin-Ping Goh and Poh-Eng Lim* \\ School of Chemical Sciences, Universiti Sains Malaysia, \\ 11800 Penang, Malaysia
}

Received 14 September 2006

\begin{abstract}
The objective of this study is to investigate the feasibility of applying potassium permanganate $\left(\mathrm{KMnO}_{4}\right)$ as the oxidant in the COD test for highly saline water samples. Initially, the COD values of various glucose standard solutions were determined by three methods, namely the standard closed reflux dichromate $\left(\mathrm{COD}_{\mathrm{Cr}}\right)$, the acidic permanganate $\left(\mathrm{COD}_{\mathrm{Mn}}\right)$ and the alkaline permanganate $\left(\mathrm{COD}_{\mathrm{OH}}\right)$ methods. The results showed that at $\mathrm{COD}$ values lower than $20 \mathrm{mg} / \mathrm{L}$, the standard dichromate method was not applicable due to its poor precision (RSD > 10\%). The $\mathrm{COD}_{\mathrm{OH}}$ method was less effective compared to the $\mathrm{COD}_{\mathrm{Mn}}$ method as the recoveries were 0.71 and 0.89 , respectively. The determination of $\mathrm{COD}_{\mathrm{OH}}$ for the standard solutions of glucose in the presence of $\mathrm{Cl}^{-}$and $\mathrm{Br}^{-}$, respectively, or both $\mathrm{Cl}^{-}$and $\mathrm{Br}^{-}$ions were conducted. The results showed that the COD values only increased $5.1 \%$ with the increase in chloride concentrations up to $35000 \mathrm{mg} \mathrm{Cl}^{-} / \mathrm{L}$. This shows that the $\mathrm{COD}_{\mathrm{OH}}$ method is a suitable method for determining the COD of highly saline water samples such as estuarine and coastal waters. The COD test was conducted for river, estuarine and coastal water samples. The results indicated that the $\mathrm{COD}_{\mathrm{OH}}$ test correlates well with the $\mathrm{COD}_{\mathrm{Cr}}$ test $\left(\mathrm{R}^{2}>0.98\right)$. The results also indicated that this $\mathrm{COD}_{\mathrm{OH}}$ test can be applied in determining the pollution trends for estuarine and coastal waters.
\end{abstract}

Keywords: COD test; saline water sample; potassium permanganate

\section{INTRODUCTION}

Chemical oxygen demand (COD) is recognized as one of the most important parameters in assessing organic pollution in aquatic systems. The COD is defined as the amount of oxygen equivalent consumed in the oxidation of organic compounds by strong oxidants (such as dichromate and permanganate). Presently, the standard closed reflux dichromate $\left(\mathrm{COD}_{\mathrm{Cr}}\right)$ method and the standard permanganate method are used in COD determination [1, 2]. The $\mathrm{COD}_{\mathrm{Cr}}$ method is not applicable to highly saline water sample containing (after dilution) more than $2000 \mathrm{mg} / \mathrm{L}$ chloride [3]. On the other hand, the standard permanganate method is only applicable to potable and surface water of which the permanganate index is between 0.5 and 10 $\mathrm{mg} / \mathrm{L}$ (about $2.5 \mathrm{mg} / \mathrm{L} \mathrm{COD)}$ with a chloride ion concentration not exceeding $500 \mathrm{mg} / \mathrm{L}$ [2].

Over the years, much research work had been carried out in an attempt to correct for the chloride interference in the $\mathrm{COD}_{\mathrm{Cr}}$ method by adding complexing agents such as $\mathrm{HgSO}_{4}$ [4 - 7], $\mathrm{Cr}^{3+}$ and $\mathrm{Al}^{3+}$ ions, respectively, [8]. However, the dichromate method presents some environmental and health problems. First, chromium (VI) is a known carcinogen. Secondly, the

\footnotetext{
* Corresponding author e-mail: pelim@usm.my
} 
discharge of mercuric ion which is needed to effect the removal of chloride may give rise to environmental problems. In terms of cost, silver sulphate is needed as a catalyst and it is expensive. As an alternative, the non-toxic cerium (IV) sulphate was used as the oxidizing agent for the determination of COD [9], but cerium (IV) sulphate was unsuitable for continuous monitoring over long periods because of its self-decomposition.

To date, no standard method has yet been suggested to determine the organic pollution in highly saline water samples (containing > $2000 \mathrm{mg} / \mathrm{L}$ chloride). The objective of this study is to develop a protocol for COD test for monitoring estuarine and coastal water pollution and to investigate the use of potassium permanganate $\left(\mathrm{KMnO}_{4}\right)$ as the oxidant in the COD test so that the use of toxic and carcinogenic compounds such as $\mathrm{HgSO}_{4}$ and $\mathrm{K}_{2} \mathrm{Cr}_{2} \mathrm{O}_{7}$ required in the standard dichromate method can be eliminated.

\section{MATERIALS AND METHODS}

A series of glucose standard solutions of 10, 20, 30, 40 and $50 \mathrm{mg} / \mathrm{L}$ COD were determined by three methods, namely the standard closed reflux dichromate $\left(\mathrm{COD}_{\mathrm{Cr}}\right)$, the acidic permanganate $\left(\mathrm{COD}_{\mathrm{Mn}}\right)$ and the alkaline permanganate $\left(\mathrm{COD}_{\mathrm{OH}}\right)$ methods. Glucose solutions containing different concentrations of chloride and bromide, respectively, or both chloride and bromide ions were prepared for the study of the halide interferences in the COD test.

River, estuarine and coastal waters samples were collected from 15 sampling sites in Penang Island. Both river and estuarine water samples were collected from flowing water near midstream. In addition, the river water samples were collected during both high and low tides. The coastal waters sampling sites were all located in the surf zone at wading depth just off the coast.

\subsection{Closed reflux, titrimetric method}

A $1.5 \mathrm{~mL}$ of $0.0333 \mathrm{M} \mathrm{K}_{2} \mathrm{Cr}_{2} \mathrm{O}_{7}$ digestion solution was added into a $16 \mathrm{x} 100 \mathrm{~mm}$ culture tube containing $2.5 \mathrm{~mL}$ sample. Subsequently, $3.5 \mathrm{~mL} \mathrm{H} \mathrm{SO}_{4}-\mathrm{Ag}_{2} \mathrm{SO}_{4}$ solution was added carefully into the tube. The cap of the tube was tightly closed and then inverted for several times to mix completely. The tube was then placed in the aluminium block digester for $2 \mathrm{~h}$ at $150{ }^{\circ} \mathrm{C}$. After digestion, the remaining dichromate was titrated with $0.0125 \mathrm{M}$ ferrous ammonium sulphate (FAS) solution and the equivalents of oxidant consumed were converted to $\mathrm{mg} \mathrm{O}_{2} / \mathrm{L}$ of sample. The detailed procedure was described in the Standard Methods [1].

\subsection{Modified permanganate method}

Exactly $10 \mathrm{~mL}$ water sample was added with $1 \mathrm{~mL}$ of $9 \mathrm{M} \mathrm{H}_{2} \mathrm{SO}_{4}$ (for $\mathrm{COD}_{\mathrm{Mn}}$ method) or $2.5 \mathrm{M}$ $\mathrm{NaOH}$ (for $\mathrm{COD}_{\mathrm{OH}}$ method) followed by $10 \mathrm{~mL}$ of $0.01 \mathrm{M} \mathrm{KMnO}_{4}$ digestion solution. The sample was heated for $30 \mathrm{~min}$ in a water bath at $96-98{ }^{\circ} \mathrm{C}$. After digestion, the sample was cooled immediately in an icebox to quench the reaction. The remaining permanganate in the sample solution was determined by titration.

\subsubsection{Titration of an acidic sample solution}

After a few grains of KI were added to the sample solution, the colour of the sample turned yellowish brown. The sample solution was titrated with $0.01 \mathrm{M} \mathrm{Na}_{2} \mathrm{~S}_{2} \mathrm{O}_{3}$ solution until the yellow solution turned pale straw colour. After that, $1 \mathrm{~mL}$ of starch solution was added to turn the colour of the solution dark blue. The titration was continued until the solution was completely colourless. The above procedure was repeated for the blank test, with $10 \mathrm{~mL}$ of distilled water replacing the sample. 


\subsubsection{Titration of an alkaline sample solution}

A few grains of KI were added to the sample solution, followed by adding $1 \mathrm{~mL}$ of $9 \mathrm{M} \mathrm{H}_{2} \mathrm{SO}_{4}$ to the solution. The sample solution was titrated with $0.01 \mathrm{M} \mathrm{Na}_{2} \mathrm{~S}_{2} \mathrm{O}_{3}$ solution until the yellow solution turned pale straw colour. After that, $1 \mathrm{~mL}$ of starch solution was added to turn the colour of the solution dark blue. The titration was continued until the solution was completely colourless. The above procedure was repeated for the blank test, with $10 \mathrm{~mL}$ of distilled water replacing the sample.

\section{RESULTS AND DISCUSSION}

\subsection{Effectiveness of permanganate method under acidic and alkaline conditions}

The COD values of various glucose standard solutions were determined by the proposed permanganate methods. The results are given in Table 1. For comparison, the COD values determined by the standard closed reflux dichromate method [1] were also included in the results. The ratio of the mean measured COD and the theoretical COD were in the range of 0.71 to 0.75 for the $\mathrm{COD}_{\mathrm{OH}}$ method and 0.89 to 0.92 for the $\mathrm{COD}_{\mathrm{Mn}}$ method. Thus, the permanganate method in acidic condition has a better recovery. This is probably due to the fact that most of the organic matters were oxidized more completely in acidic than in alkaline conditions [10].

Table 1: $\quad$ Comparison of COD values of glucose standards using different methods.

\begin{tabular}{|c|c|c|c|c|c|}
\hline Methods & $\begin{array}{l}\text { Theoretical } \\
\text { COD, mg/L }\end{array}$ & $\begin{array}{c}\text { Mean } \\
\text { measured } \\
\text { COD, mg/L }\end{array}$ & $\begin{array}{c}\text { Standard } \\
\text { deviations, } \\
\text { mg/L }\end{array}$ & $\begin{array}{c}\text { Relative } \\
\text { standard } \\
\text { deviations, \% }\end{array}$ & $\begin{array}{c}\text { Recover, } \\
\%\end{array}$ \\
\hline \multirow[t]{6}{*}{$\mathrm{COD}_{\mathrm{OH}}$} & 0.0 & 0.3 & 0.31 & - & - \\
\hline & 10.0 & 7.5 & 0.23 & 3.07 & 75 \\
\hline & 20.0 & 14.8 & 0.23 & 1.55 & 74 \\
\hline & 30.0 & 21.6 & 0.40 & 1.85 & 72 \\
\hline & 40.0 & 28.5 & 0.40 & 1.40 & 71 \\
\hline & 50.0 & 36.1 & 0.46 & 1.27 & 72 \\
\hline \multirow[t]{6}{*}{$\mathrm{COD}_{\mathrm{Mn}}$} & 0.0 & 0.4 & 0.35 & - & - \\
\hline & 10.0 & 9.2 & 0.23 & 2.50 & 92 \\
\hline & 20.0 & 18.1 & 0.46 & 2.54 & 91 \\
\hline & 30.0 & 27.6 & 0.40 & 1.45 & 92 \\
\hline & 40.0 & 36.3 & 0.61 & 1.68 & 91 \\
\hline & 50.0 & 44.7 & 0.46 & 1.03 & 89 \\
\hline \multirow[t]{6}{*}{$\mathrm{COD}_{\mathrm{Cr}}$} & 0.0 & 3.0 & 2.15 & - & - \\
\hline & 10.0 & 11.0 & 3.05 & 26.99 & 110 \\
\hline & 20.0 & 21.0 & 3.06 & 14.57 & 105 \\
\hline & 30.0 & 28.0 & 1.15 & 4.11 & 93 \\
\hline & 40.0 & 38.0 & 2.31 & 6.08 & 95 \\
\hline & 50.0 & 48.0 & 0.58 & 1.21 & 96 \\
\hline
\end{tabular}


The relative standard deviations for the $\mathrm{COD}_{\mathrm{OH}}$ and $\mathrm{COD}_{\mathrm{Mn}}$ methods were all below $5 \%$. In contrast, the relative standard deviations for the $\mathrm{COD}_{\mathrm{Cr}}$ method were higher than $10 \%$ for the determination of samples having COD value lower than $20 \mathrm{mg} / \mathrm{L}$. The results in Table 1 indicate that the $\mathrm{COD}_{\mathrm{OH}}$ and $\mathrm{COD}_{\mathrm{Mn}}$ methods are more suitable for the COD determination of samples having COD value lower than $20 \mathrm{mg} / \mathrm{L}$ compared to the $\mathrm{COD}_{\mathrm{Cr}}$ method.

\subsection{Effect of chloride and bromide ions on the determination of COD}

One of the major difficulties encountered in $\mathrm{COD}_{\mathrm{Mn}}$ and $\mathrm{COD}_{\mathrm{Cr}}$ methods is the inability of the methods to compensate for positives interference caused by the oxidation of chloride present in water sample [4 - 7]. The standard method procedure for eliminating the chloride interference involves the addition of $\mathrm{HgSO}_{4}$ to form a complex and thus prevent the oxidation of chloride [1, 7, 11]. As the main objective of this research is to develop a protocol for COD test for monitoring the estuarine and coastal water pollutions, both $\mathrm{COD}_{\mathrm{Mn}}$ and $\mathrm{COD}_{\mathrm{Cr}}$ methods are clearly not suitable for the analysis due to their low ability to compensate for the chloride interference.

The effects of chloride, bromide or both chloride and bromide, respectively, on the determination of $\mathrm{COD}_{\mathrm{OH}}$ were investigated. Glucose standards of $20 \mathrm{mg} / \mathrm{L} \mathrm{COD}$ were spiked with varying amounts of either chloride, bromide or both chloride and bromide in order to determine the limiting concentration at which the interference was significant. To prevent the oxidation of halogen compounds by permanganate solution in the test sample, the digestion reaction was carried out in alkaline condition first and then acidifying just before the titration.

The results are shown in Fig. 1, it was observed that the COD value increased about $5.1 \%$ with the increase in chloride concentrations up to $35000 \mathrm{mg} \mathrm{Cl} / \mathrm{L}$. The corresponding interferences of bromide or chloride together with bromide were, respectively, 5.9 and $6.7 \%$. The results indicate that $\mathrm{COD}_{\mathrm{OH}}$ method is a suitable method for analyzing high salinity water samples such as estuarine and coastal waters because the change of COD value against the interferences of halide ions was relatively minor.

The results compare quite favorably with the result reported by Fujimori [10] for the determination of COD for artificial seawater with salinity varying from 0 to $3.4 \%$. Fujimori reported that the chemiluminescence signals increased about $10 \%$ with the increase in salinity. The results obtained by Fujimori were slightly higher than those obtained in this study probably because the experiment conducted by Fujimori et al. was in acidic condition. In acidic condition, the oxidizing ability of the $\mathrm{KMnO}_{4}$ is stronger than in alkaline condition.

\subsection{Determination of COD for environmental water samples}

\subsubsection{River water}

Initial attempt for this study was to examine the correlation between $\mathrm{COD}_{\mathrm{OH}}$ and $\mathrm{COD}_{\mathrm{Cr}}$ for high salinity environmental samples, but the effort did not succeed because the oxidation of chloride was erratic. Alternatively, an effort to correlate between $\mathrm{COD}_{\mathrm{OH}}$ and $\mathrm{COD}_{\mathrm{Cr}}$ for river water samples was undertaken.

Samples were collected from Sungai Pinang the major river in Penang Island at five sampling points namely R1 to R5 (Fig. 2). All the sampling points were located in the urban area of Georgetown. Considering that sampling points R4 and R5 were located at the tidal part of Sungai Pinang, only samples collected from R1 to R3 were used to determine the correlation between $\mathrm{COD}_{\mathrm{OH}}$ and $\mathrm{COD}_{\mathrm{Cr}}$. Nevertheless, the COD values determined at all the sampling points were used to study the pollution trend of Sungai Pinang. 
(a)
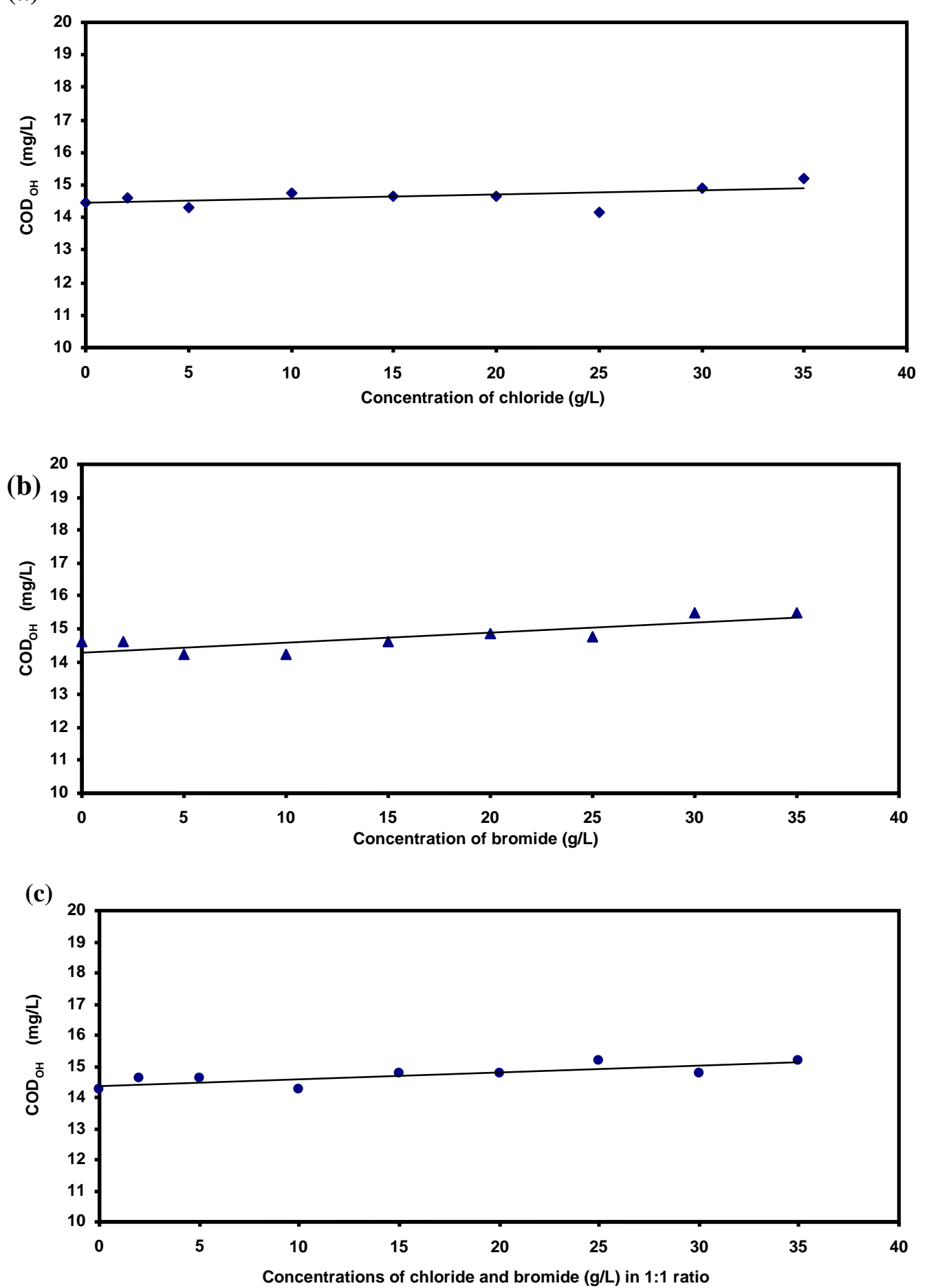

Fig. 1: Effect of (a) $\mathrm{Cl}^{-}$, (b) $\mathrm{Br}^{-}$and (c) both $\mathrm{Cl}^{-}$and $\mathrm{Br}^{-}$concentrations on the determination of $C O D_{O H}$ for the standard solutions of $20 \mathrm{mg} / \mathrm{L}$ theoretical COD. 


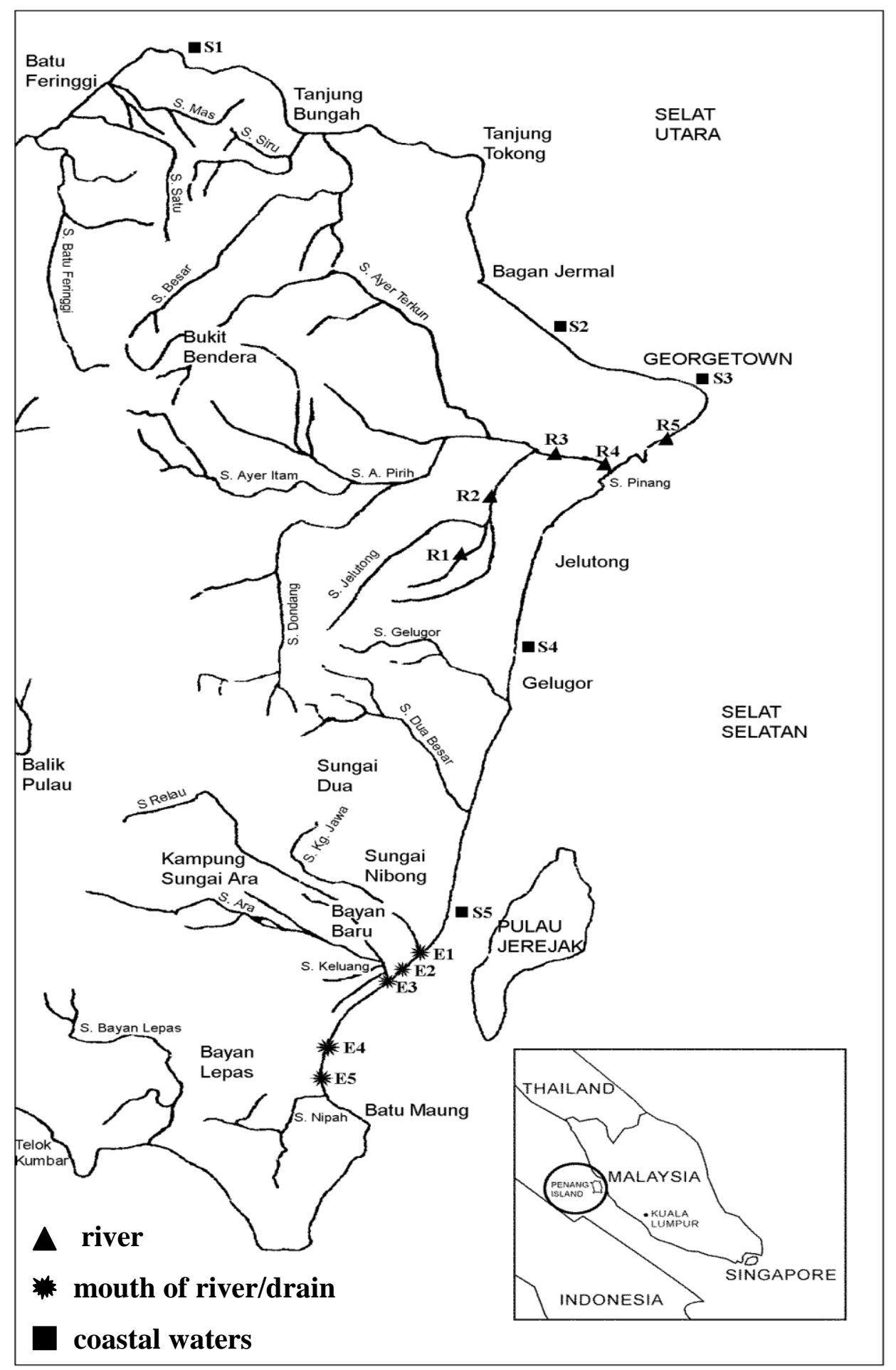

Fig. 2: $\quad$ Sampling locations for environmental water samples. 


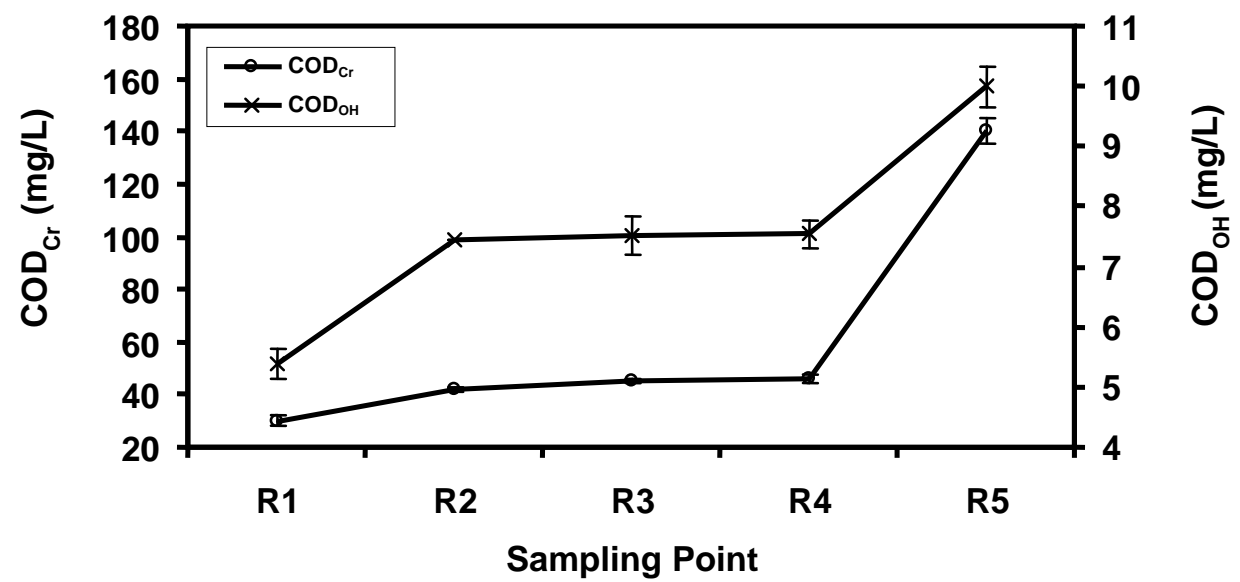

(a)

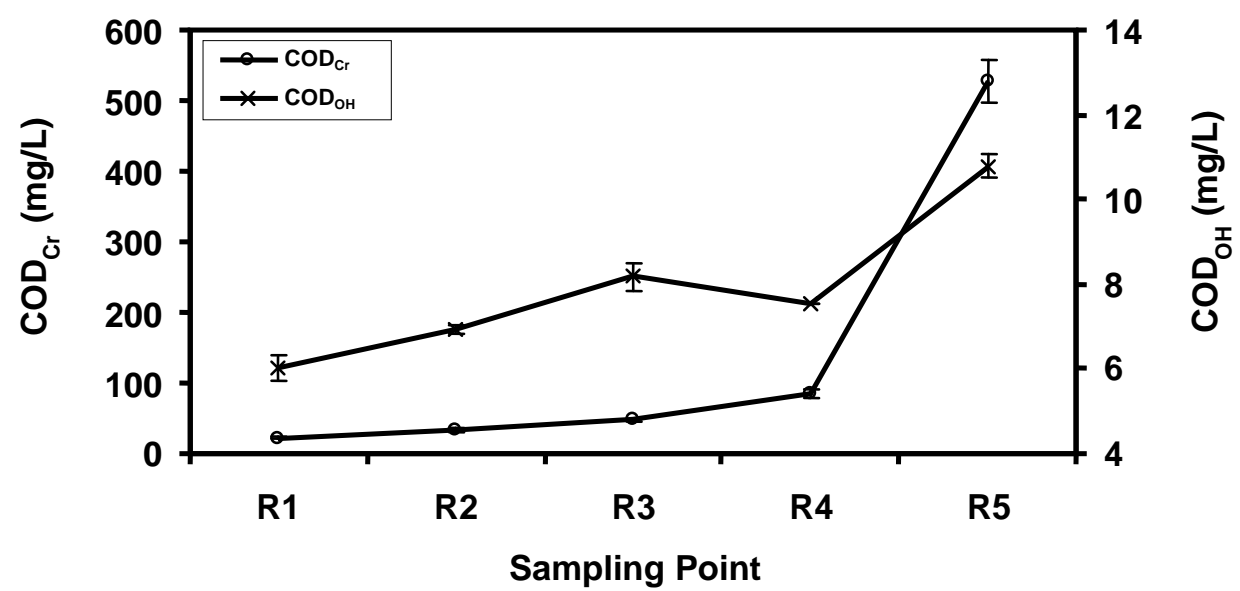

(b)

Fig. 3: Determination of COD values for river water samples during (a) low tide and (b) high tide.

The results in Fig. 3 indicate that there was an increasing pollution trend from the upstream to the estuary of Sungai Pinang. Besides, they also indicate that the $\mathrm{COD}_{\mathrm{OH}}$ method can accommodate the chloride interference in the environmental samples such as river water with tidal effect. The decrease of $\mathrm{COD}_{\mathrm{OH}}$ for $\mathrm{R} 4$ [Fig. 3(b)] was probably due to the intrusion of seawater during high tide. Surprisingly, the $\mathrm{COD}_{\mathrm{OH}}$ for R5 which was expected to be lower due to greater intrusion was higher than R4. One reason for this might be that sample collected at R5 was more polluted due to the location of R5 near the residential houses built on the reclaim land along the estuary. Owing to the absence of proper sanitation system, most of the wastes were directly discharged into the river.

The coefficient of determination $\left(\mathrm{R}^{2}\right)$ for the $\mathrm{COD}_{\mathrm{OH}}$ and $\mathrm{COD}_{\mathrm{Cr}}$ was calculated. The $\mathrm{R}^{2}$ value was 0.997 for the samples collected during high tide. For the samples collected during low tide 
the $\mathrm{R}^{2}$ was 0.983 . As the values of $\mathrm{R}^{2}$ obtained were all close to 1.00 , this indicates that both the $\mathrm{COD}_{\mathrm{Cr}}$ and $\mathrm{COD}_{\mathrm{OH}}$ methods correlate well (Fig. 3).

\subsubsection{Estuarine and coastal waters}

Figure 4(a) shows the results of COD for samples collected at the mouths of the waterways draining into the coastal waters. The samples were collected at five sampling points namely E1 to E5 (Fig. 2). The results from the study show that the $\mathrm{COD}_{\mathrm{OH}}$ method is applicable in indicating the pollution trend of estuarine waters, the COD results from the dichromate method was quoted for comparison. The results also show that the standard method was unable to compensate for the chloride interference.

As it has been proven that the $\mathrm{COD}_{\mathrm{Cr}}$ is not suitable for the monitoring of water pollution for estuarine waters, only the $\mathrm{COD}_{\mathrm{OH}}$ method was used to determine the COD for coastal waters. The coastal water samples were collected at five sampling points namely S1 to S5 (Fig. 2). The results indicate that the water at $\mathrm{S} 2 \mathrm{had}$ a higher COD value compared to other sampling points (Fig. 4(b)). The location of S2 was off Gurney, a popular tourist spot for hawker food which might be a source for pollution.

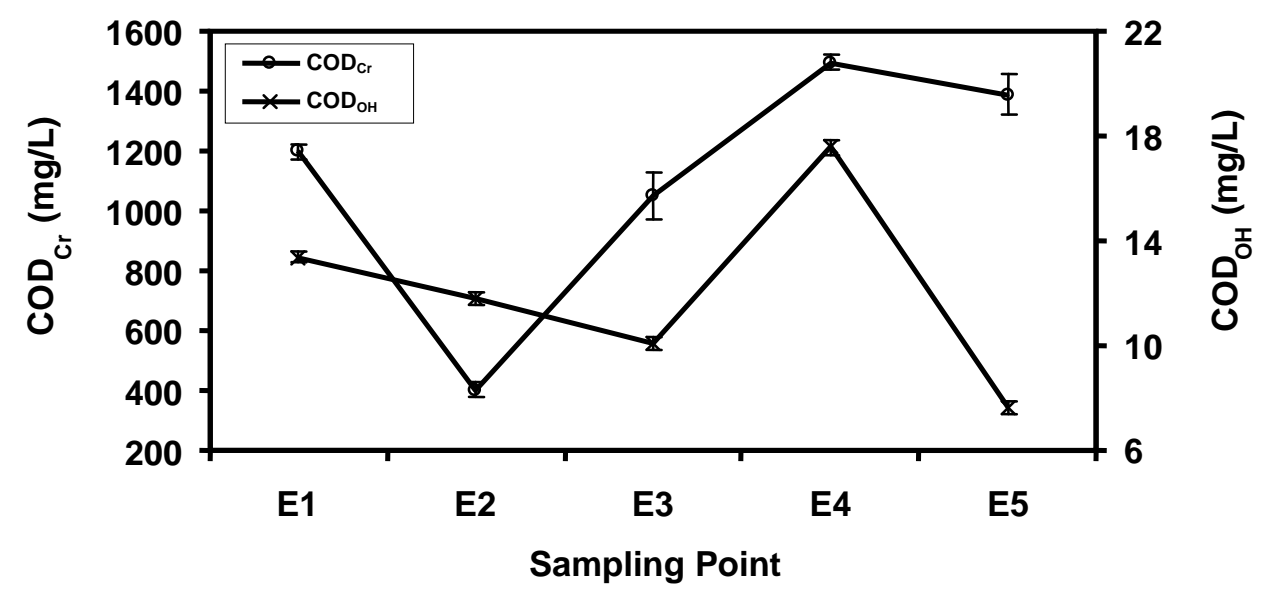

(a) 


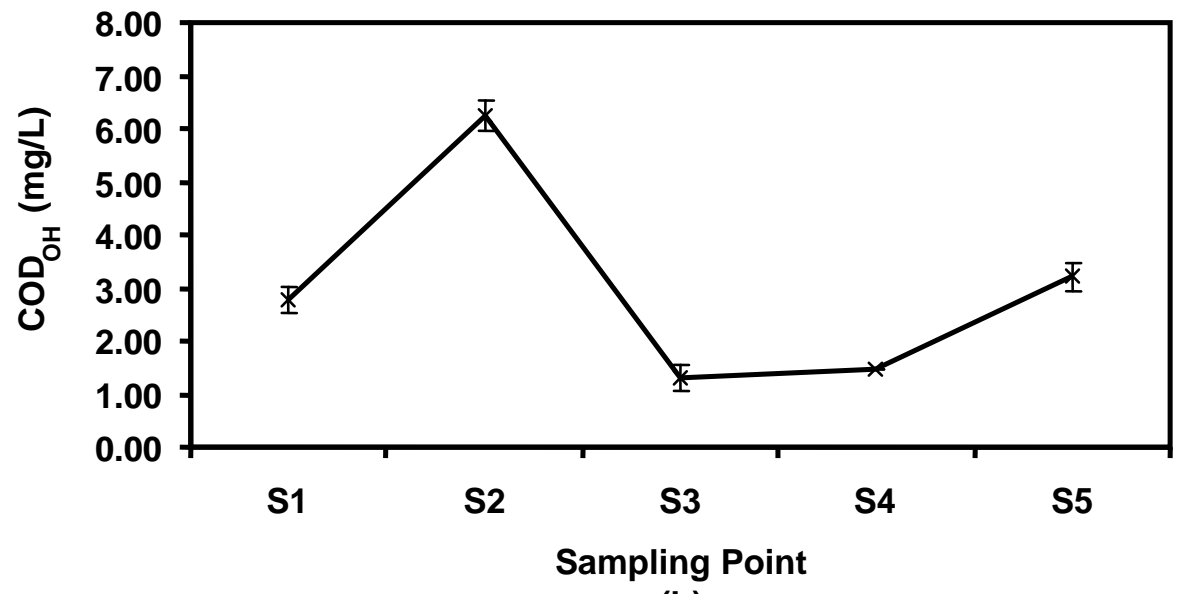

(b)

Fig. 4: Determination of COD values for (a) estuarine waters and (b) coastal waters.

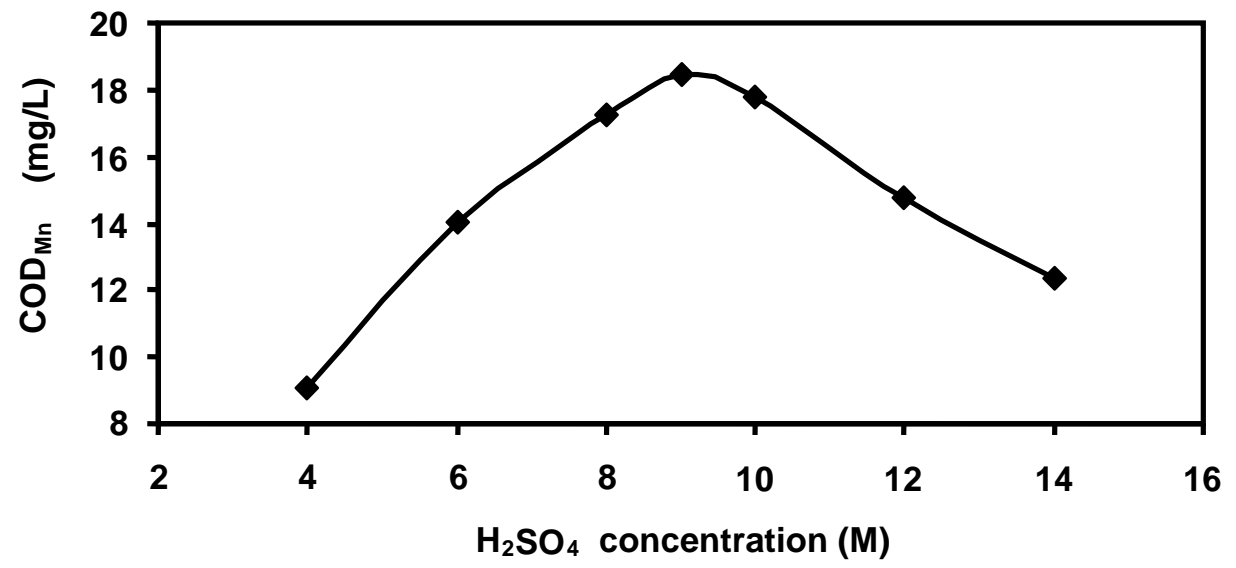

(a)

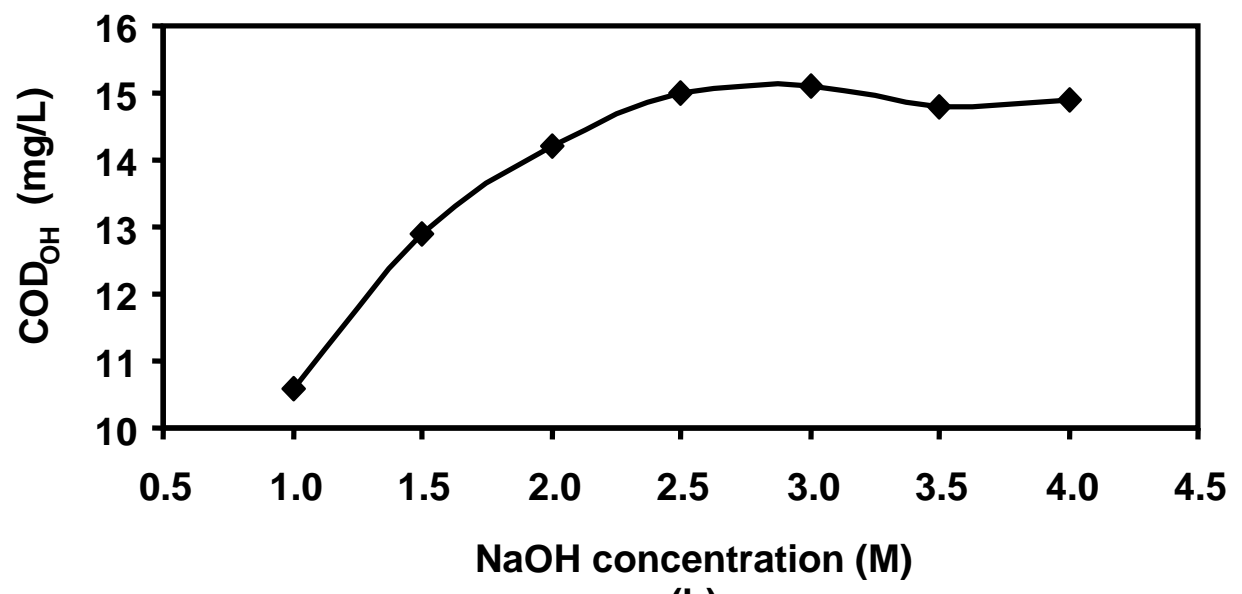

(b) 


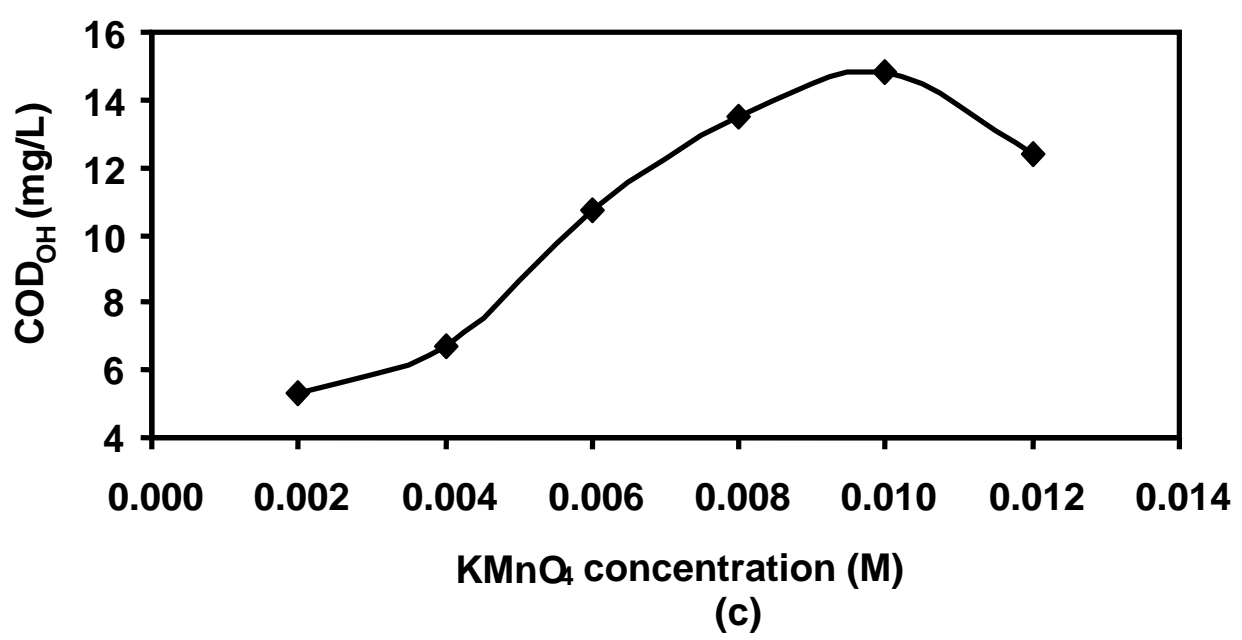

Fig. 5: Effects of (a) $\mathrm{H}_{2} \mathrm{SO}_{4}$ concentration on $\mathrm{COD}_{\mathrm{Mn}}$, (b) $\mathrm{NaOH}$ concentration on $\mathrm{COD}_{\mathrm{OH}}$ and (c) $\mathrm{KMnO}_{4}$ concentration on $\mathrm{COD}_{\mathrm{OH}}$.

\subsection{Optimum conditions for $\mathrm{COD}_{\mathrm{Mn}}$ and $\mathrm{COD}_{\mathrm{OH}}$ tests}

Over the years, research had been done to study the effect of $\mathrm{H}_{2} \mathrm{SO}_{4}$ concentration on the $\mathrm{COD}_{\mathrm{Mn}}$ test $[10,12]$. Figure 5(a) shows the effect of $\mathrm{H}_{2} \mathrm{SO}_{4}$ concentration on $\mathrm{COD}_{\mathrm{Mn}}$ analysis and the results indicate that $9 \mathrm{M} \mathrm{H}_{2} \mathrm{SO}_{4}$ was the optimum concentration. The effect of $\mathrm{NaOH}$ concentration on the determination of $\mathrm{COD}_{\mathrm{OH}}$ was also examined in the range of 0 to $4.0 \mathrm{M}$. Figure 5(b) shows that $2.5 \mathrm{M} \mathrm{NaOH}$ was the optimum concentration. Some researchers [10, 12] had reported that $\mathrm{KMnO}_{4}$ concentration affects the digestion reaction. The results in Fig. 5(c) indicate that $0.010 \mathrm{M} \mathrm{KMnO}_{4}$ was the optimum concentration for the determination of $\mathrm{COD}_{\mathrm{OH}}$. In addition, the effects of the digestion period and the digestion temperature on the $\mathrm{COD}_{\mathrm{OH}}$ test were also studied. It was observed that $30 \mathrm{~min}$ of digestion period was sufficient and there was an increase of $9.0 \%$ in the recovery of $\mathrm{COD}_{\mathrm{OH}}$ test when the samples were heated at $96-98^{\circ} \mathrm{C}$ compared to that at $80^{\circ} \mathrm{C}[2,13]$.

\section{CONCLUSIONS}

The $\mathrm{COD}_{\mathrm{OH}}$ method yielded COD values which exhibited similar trend as the COD values obtained from the standard test for river water samples. The $\mathrm{COD}_{\mathrm{OH}}$ test is applicable regardless of the tidal effects making it a better monitoring parameter for river water pollution. With this $\mathrm{COD}_{\mathrm{OH}}$ test, the COD for the estuarine and coastal waters can be determined easily without additional procedure to correct for the interference of chloride.

Over the years, the consumption of expensive reagents such as $\mathrm{AgSO}_{4}$ and the difficulty of disposing of highly toxic mercury, silver and chromium waste is a serious problem faced by most analytical laboratories. The use of $\mathrm{KMnO}_{4}$ as an oxidizing agent in the COD test can help to avoid the use of toxic compounds such as $\mathrm{HgSO}_{4}$ and $\mathrm{K}_{2} \mathrm{Cr}_{2} \mathrm{O}_{7}$ which are required in the standard method. Thus, this $\mathrm{COD}_{\mathrm{OH}}$ test is considered a low cost and environmentally friendly method.

\section{REFERENCES}


1. Clesceri, L.S., Greenberg, A.E., and Eaton, A.D. (1998), Standard methods for the examination of water and wastewater, 20th edition, American Public Health Association, Washington, DC.

2. Environmental and Pollution Standards Policy Committee (1995), BS 6068-2.32: Water quality - Determination of permanganate index, British Standards Institution, London.

3. Environmental and Pollution Standards Policy Committee (1988), BS 6068-2.34: Water quality - Part 2: Physical, chemical and biochemical methods - Section 2.34 Method for the determination of the chemical oxygen demand, British Standards Institution, London.

4. Cameron, W.M. and Moore, T.B. (1957), The influence of chloride on the dichromate-value test, Analyst, vol. 82, pp. 677-682.

5. Dobbs, R.A. and Williams, R.T. (1963), Elimination of chloride interference in the chemical oxygen demand test, Analytical Chemistry, vol. 35, pp. 1064-1067.

6. Cripps, J.M. and Jenkins, D. (1964), A COD method suitable for the analysis of highly saline waters, Analytical Chemistry, vol. 36, pp. 1240-1246.

7. Baumann, F.J. (1974), Dichromate reflux chemical oxygen demand - A Proposed method for chloride correction in highly saline wastes, Analytical Chemistry, vol. 46, pp. 13361338 .

8. Ho, C.H., Lee, K.F., and Lim P.E. (2003), Minimizing the use of mercuric salts for chloride and bromide corrections in chemical oxygen demand test, Malaysian Journal of Chemistry, vol. 5, pp. 67-72.

9. Korenaga, T., Zhou, X., Okada, K., Moriwake, T., and Shinoda, S. (1993), Determination of chemical oxygen demand by a flow-injection method using cerium (IV) sulphate as oxidizing agent, Analytica Chimica Acta, vol. 272, pp. 237-244.

10. Fujimori, K., Ma, W., Kawakami, T.M., and Shibutani, T. (2001), Chemiluminescence method with potassium permanganate for the determination of organic pollutants in seawater, Analytical Sciences, vol. 17, pp. 975-978.

11. Korenaga, T. and Ikatsu, H.Y. (1982), The determination of chemical oxygen demand in waste-waters with dichromate by flow injection analysis, Analytica Chimica Acta, vol. 141, pp. 301-309.

12. Montalvo, S.I. and JR Ingle, J.D. (1993), Chemiluminescence during the oxidation of alcohols by permanganate: Application to the determination of ethanol in gin, Talanta, vol. 40, pp. 167-172.

13. Li, B.X., Zhang, Z.J., Wang, J., and Xu, C.L. (2003), Chemiluminescence system for automatic determination of chemical oxygen demand using flow injection analysis, Talanta, vol. 61, pp. 651-658. 